\title{
Enzymatic Interesterification in Supercritical Carbon Dioxide
}

\author{
Young Min ChI, Kozo NaKamura and Toshimasa Yano \\ Department of Agricultural Chemistry, The University of Tokyo, Bunkyo-ku, Tokyo 113, Japan \\ Received January 8, 1988
}

\begin{abstract}
An enzymatic reaction with supercritical carbon dioxide $\left(\mathrm{SCCO}_{2}\right)$ as the reaction medium was investigated. Lipase could catalyze the batch type reaction of hydrolysis and interesterification (acidolysis) in $\mathrm{SCCO}_{2}$ at $50^{\circ} \mathrm{C}$ and $29.4 \mathrm{MPa}$. The time course of interesterification was influenced by the water content as well as by the kind of reaction medium. The initial velocities of hydrolysis and interesterification were greater in $\mathrm{SCCO}_{2}$ than in $n$-hexane when the water content increased. A part of this difference in reaction velocity was supposed to be due to water, a modifier of the solvent, the solubility of which in $\mathrm{SCCO}_{2}$ was estimated to be a hundred times that in $n$-hexane.
\end{abstract}

Supercritical fluids are currently receiving attention as to extraction processes, because they offer a number of advantages over conventional liquid solvents. Among these advantages are a low viscosity and a high diffusivity, allowing rapid extraction compared with organic solvents. Another advantage is the ability to control the solubility of the solute by regulation of the temperature and/or pressure. This feature permits a simplified separation step. ${ }^{1)}$

In particular, supercritical $\mathrm{CO}_{2}\left(\mathrm{SCCO}_{2}\right)$ is of special interest to the food, pharmaceutical and biochemical industries for several reasons. Carbon dioxide is safe for human beings and its critical temperature is $31.3^{\circ} \mathrm{C}$, allowing heat labile substances to be processed without thermal denaturation or decomposition. Carbon dioxide is a very inert solvent, and it was reported that proteins and enzymes were neither significantly denatured nor inactivated in $\mathrm{SCCO}_{2} \cdot{ }^{2 \sim 4}$ Its non-toxicity, non-flammability, environmental acceptability and availability at low cost have made $\mathrm{CO}_{2}$ the most popular medium for investigation to date.

While the use of $\mathrm{SCCO}_{2}$ has been mainly for extractions, the application of this medium to reactions, for which it has excellent properties, has not yet been extensively explored. Several examples of chemical reactions in supercritical fluids (SCF) have been explained in a review. ${ }^{51}$ There had been, however, no report on a SCFbiochemical reaction when we started to study the lipase reaction in $\mathrm{SCCO}_{2}{ }^{6,7)}$ Recently, two papers were published on enzymatic reactions in $\mathrm{SCCO}_{2}$. One was a paper by Randolph et $a l .{ }^{8)}$ that described the hydrolysis of $p$-nitrophenyl phosphate in $\mathrm{SCCO}_{2}$ with alkaline phosphatase. The other was by Hammond et al., ${ }^{9)}$ who found that mushroom polyphenol oxidase can oxidize phenols in $\mathrm{SCCO}_{2}$ and also in supercritical fluoroform, with regiospecificity. However, little information is available, because the experimental data were very insufficient and showed only the possibility of the use of $\mathrm{SCCO}_{2}$ as a enzymatic reaction medium.

Recently, a large number of studies have been devoted to the enzymatic production of useful glycerides* which cannot be obtained through conventional chemical interesterification. ${ }^{10)}$ In those enzymatic production systems, the regiospecificity of some lipases is available, and organic solvents are used to overcome the insolubility of the substrates and the products in water. ${ }^{11,12)}$ Since the inter-

* The chemical term glyceride or tri(di, mono)glyceride is used here in place of the formal expression of acylglycerol or tri(di, mono)acylglycerol, respectively. 
esterification reaction is based on the manipulation of the chemical equilibrium of a thermodynamically reversible reaction, ${ }^{13}$ the control of the water content in the reaction system is of crucial importance. The yield of triglycerides and the degree of interesterification depend on the water content, ${ }^{11,12)}$ and the initial reaction rate of alcoholysis was reported to increase with an increase in the water content. ${ }^{14)}$ Both hydrophilic and hydrophobic substrates should be in good contact with each other in the synthetic reaction for triglycerides, and a membrane reactor was studied for this purpose. ${ }^{15)}$

The enzymatic synthesis or interesterification of triglycerides is a good example of a biochemical reaction to be tested in $\mathrm{SCCO}_{2}$, because triglycerides and fatty acids are soluble in $\mathrm{SCCO}_{2} \cdot{ }^{16)}$ In the present study, we chose the interesterification of triolein and stearic acid catalyzed by lipase to elucidate the characteristics of $\mathrm{SCCO}_{2}$ as a reaction medium.

\section{MATERIALS AND METHODS}

Substrates. Triolein and stearic acid (both $99 \%$ pure) were purchased from Sigma Chemical Co., U.S.A.

Enzymes and supports. The lipases from Rhizopus delemar (Seikagaku Kogyo Co., Ltd.), Rhizopus japonicus (Osaka Saikin Kenkyu Jyo, Co., Ltd.), Alcaligenes sp. (Meito Sangyo Co., Ltd.) and Mucor miehei (Novo Industry, Japan) were used in the experiments. The latter three enzymes were kindly presented by the respective companies. All four lipases have been reported to exhibit 1,3-regiospecificity. The suports used were purchased from Wako Pure Chemical Industries. Ltd. (Johns-Manville, Celite No. 503) or donated by Sasaki Chemical Co., Ltd. (Duolite A-568). The specific surface area and pore diameter were measured with a Flow Sorp 2300 (Micrometrics, U.S.A.) and an Auto Pore 9200 (Micrometrics, U.S.A.), respectively. The characteristics of the supports are presented in Table I. The specific activity of each lipase used, units per $g$ of pure or crude enzyme, was the value

Table I. Characteristics of the Lipases and Supports

\begin{tabular}{lcccc}
\hline \multicolumn{1}{c}{ Origin of lipase } & $\begin{array}{c}\text { Specific activity } \\
(\times 1000 \mathrm{U} / \mathrm{g})^{a}\end{array}$ & Support & $\begin{array}{c}\text { Specific surface } \\
\text { area }\left(\mathrm{m}^{2} / \mathrm{g}\right)\end{array}$ & $\begin{array}{c}\text { Pore diameter }^{b} \\
(\AA)\end{array}$ \\
\hline $\begin{array}{l}\text { Rhizopus delemar } \\
\text { Rhizopus japonicus }\end{array}$ & $600^{*}$ & Celite & 1.54 & 18,300 \\
Alcaligenes sp. & $1000^{*}$ & Celite & 1.54 & 18,300 \\
Mucor miehei & $100^{*}$ & No use & -- & $100 \sim 600$ \\
\hline
\end{tabular}

a One unit is the amount of enzyme which liberates one micromole of fatty acid per minute. The activity of each lipase was assayed through hydrolysis of olive oil emulsion* or tributyrin**.

${ }^{b}$ The pore diameter of Celite is $4 V / A$, where $V$ is the total intrusion volume and $A$ the total pore area.

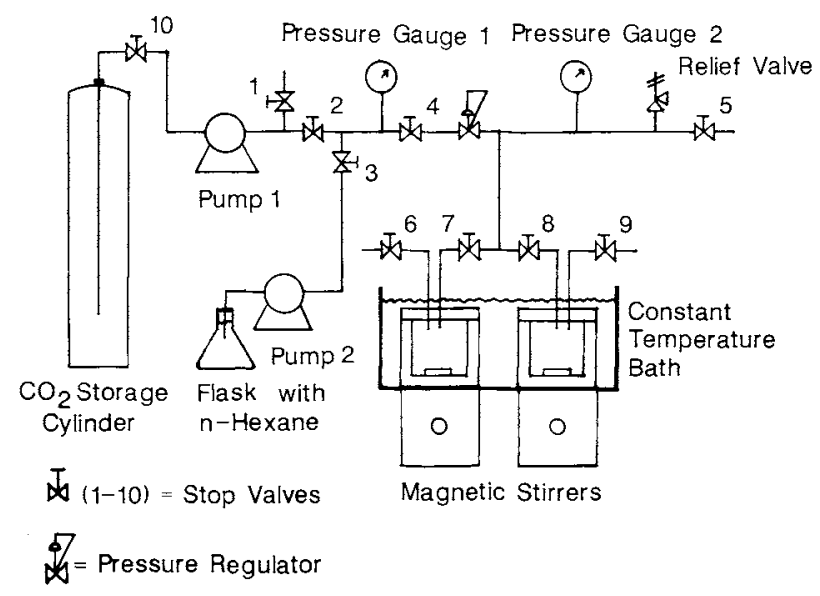

FIG. 1. Scheme of the Experimental Apparatus. 
reported by the respective maker.

Immobilization. Enzyme immobilization was carried out in $n$-hexane. That is, $3 \mathrm{~g}$ of a support, which contained $c a$. $24 \%$ (w/w) 0.3 M TES buffer (i.e., $N$-Tris(hydroxymethyl)methyl-2-aminoethane sulfonic acid, $\mathrm{pH} 6.5$ ), was put into $100 \mathrm{ml}$ of water-saturated $n$-hexane, and then $450 \mathrm{mg}$ of lipase powder was added little by little with mild magnetic stirring. After adsorptive immobilization, the $n$-hexane was decanted. The two lipases of Rhizopus origin were immobilized in this way, while the Alcaligenes sp. lipase, which is hydrophobic, was used for the reaction without immobilization. The immobilized Mucor miehei lipase was a commercial product.

Control of the water content. Before the use of an immobilized enzyme, its water content was decreased through dehydration for $48 \mathrm{hr}$ in a vacuum desiccator containing $\mathrm{P}_{2} \mathrm{O}_{5}$ powder. The water content of the desiccated immobilized enzyme was calculated by comparison of its weight before and after it was heated at $105^{\circ} \mathrm{C}$ for $3 \mathrm{hr}$.

Reaction experiments. The experimental apparatus with $\mathrm{SCCO}_{2}$ as the reaction medium is schematically shown in Fig. 1, where two reactors are used, although the maximum number of reactors usable was six. Each reactor was a $40 \mathrm{ml}$ high pressure vessel, into which $0.2 \mathrm{~g}$ immobilized lipase, $0.2 \mathrm{~g}$ triolein, $0.2 \mathrm{~g}$ stearic acid and a certain a mount of $0.3 \mathrm{M}$ TES buffer were loaded. The amount of each of triolein and stearic acid corresponds, respectively, to a concentration of $5 \mathrm{~g} / 1$. The reaction was carried out in the same way as described previously. ${ }^{7)}$

A glass vessel of $60 \mathrm{ml}$ volume was used in the reaction experiments when $40 \mathrm{ml}$ of water-saturated $n$-hexane was used as the reaction medium. To prevent volatilization of the $n$-hexane, a cooler similar to a Liebig condenser was connected to the top of the reactor. The reactor was then put into a bath at a constant temperature and then magnetic stirring was started to initiate the reaction. The reactor was cooled with tap water when the reaction was stopped, and $20 \mathrm{ml}$ of $n$-hexane was immediately taken out of the reactor and subjected to analysis.

Analysis. The solvent containing glycerides and fatty acids was evaporated, and then the residue was redissolved in $5 \mathrm{ml}$ of tetrahydrofuran. This solution was used for the analysis. The HPLC used was a JASCO TRIROTAR equipped with a Shodex SE-11 RI detector, and the separation of reaction products was achieved on an Inertsil ODS column $(4.6 \mathrm{~mm} \phi \times 250 \mathrm{~mm}$. Gasukuro Kogyo Co.). The solvent system employed was acetonitriletetrahydrofuran-dichloromethane-acetic acid (70:20: $20: 0.8[\mathrm{v} / \mathrm{v}])$. Aliquots of $10 \mu \mathrm{l}$ of the sample solution were introduced with a microsyringe through a injector, at a solvent flow rate of $0.9 \mathrm{ml} / \mathrm{min}$. The chromatographic analysis was carried out in a room at a constant tempera- ture, $20 \pm 2^{\circ} \mathrm{C}$. Residual triglyceride and extent of incorporation of stearic acid were defined as follows, using the mole concentrations of three kinds of triglycerides, and they were calculated in the equilibrium state of the reaction;

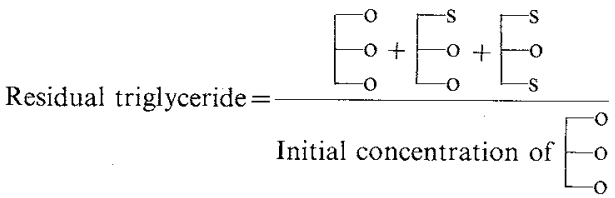

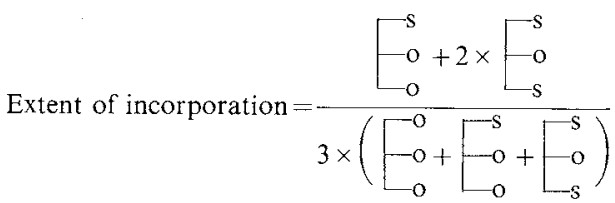

In the above equations, $\mathrm{E}$ is the glycerol moiety, and the letters, o and $s$, denote oleate and stearate, respectively.

\section{RESULTS AND DISCUSSION}

\section{Effects of the reaction conditions}

How the reaction conditions could influence hydrolysis and interesterification in $\mathrm{SCCO}_{2}$ was investigated in preliminary experiments. When the lipase of Rhizopus delelmar was used without a disperser, Celite, the hydrolysis of triolein could proceed well under the conditions of $35^{\circ} \mathrm{C}$ and $14.7 \mathrm{MPa}$. The extent of interesterification, however, was very insuffcient, that is, only about $8 \%$. This result was supposed to be due to the poor solubility of stearic acid, and therefore the reaction temperature was increased to $50^{\circ} \mathrm{C}$, which was, however, still lower than the melting point of stearic acid $\left(71^{\circ} \mathrm{C}\right)$. A diperser was also expected to have an effect, and so Celite was added to the reactor at $20 \mathrm{~g} / \mathrm{l}$-reactor. The extent of interesterification with a reaction time of $6 \mathrm{hr}$ was much improved, and the maximum value of $32 \%$ was attained when the buffer content in the Celite was 25 to $35 \%$. Above this buffer content, the extent of interesterification as well as the amount of residual triglycerides decreased, probably due to the lower solubility of stearic acid in $\mathrm{SCCO}_{2}$ with a higher water content. In the case of the Rhizopus delemar lipase, it was necessary to use $30 \mathrm{mg}$ of the enzyme in a $40 \mathrm{ml}$ reactor when the reaction could be equilibrated in $6 \mathrm{hr}$ un- 


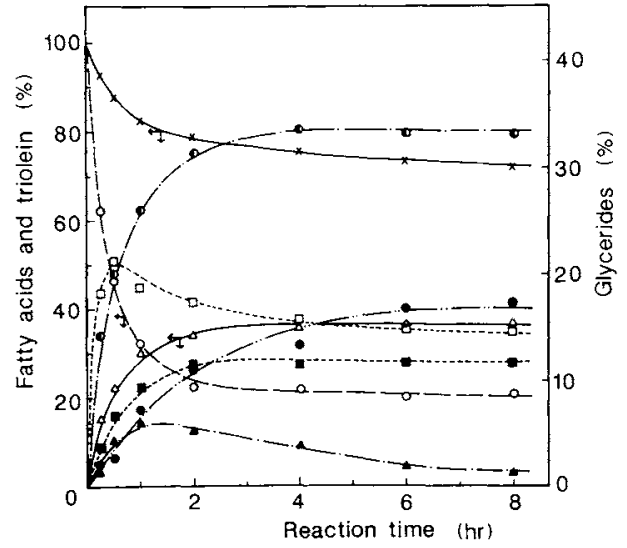

(a)

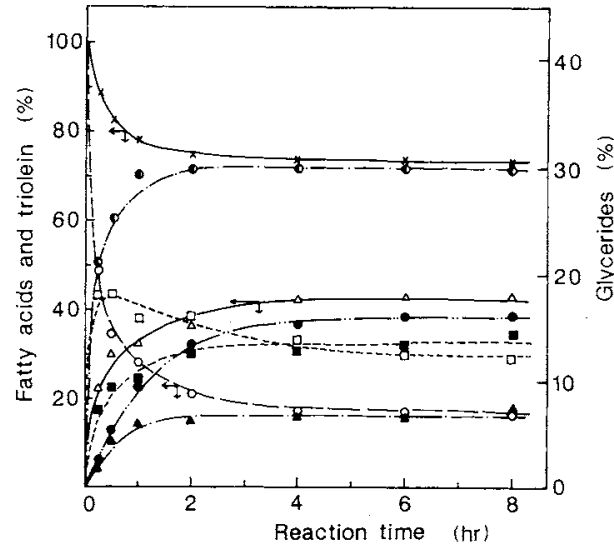

(b)

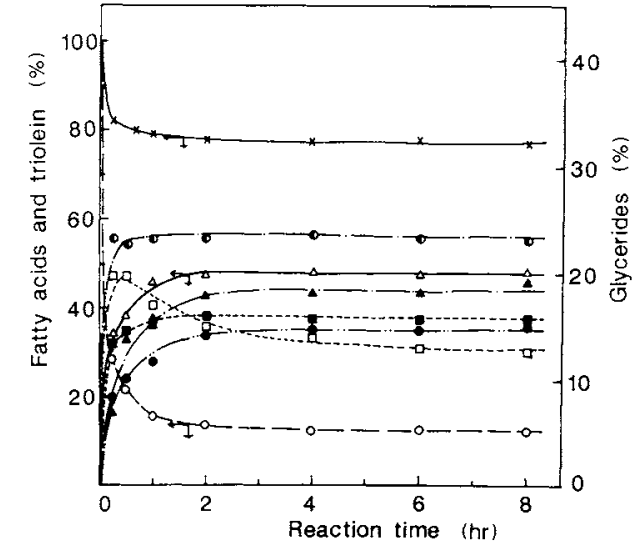

(c)

FIG. 2. Time Courses of the Reaction in $\mathrm{SCCO}_{2}$ with the Mucor miehei Lipase Immobilized on Duolite.

Water content $(\%$ w/w-carrier): (a) 0.0882 ; (b) 2.09 ; (c) 10.01. $\triangle(-)$, oleic acid; $\times(-)$, stearic acid; $\bigcirc(-\longrightarrow)$, triolein;

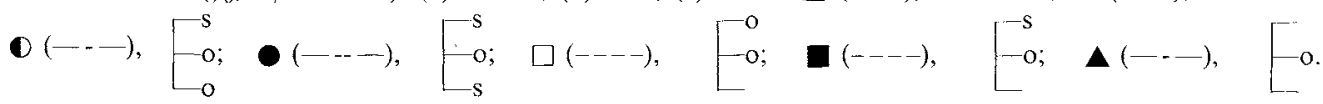




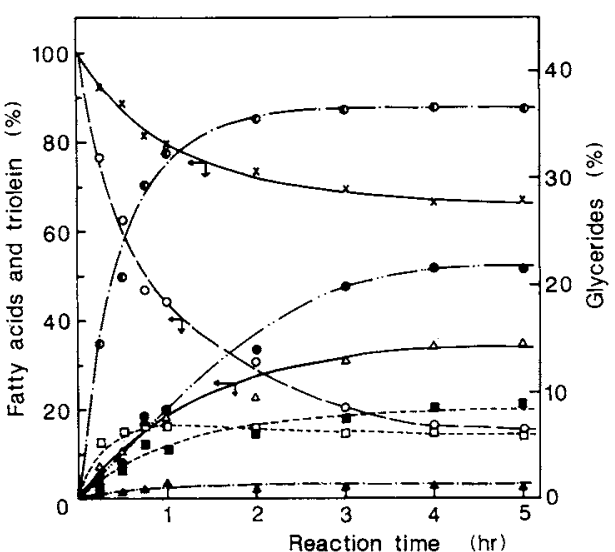

(a)

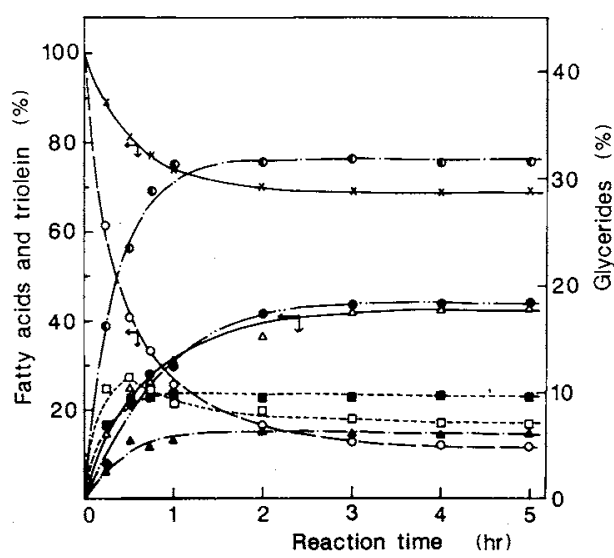

(b)

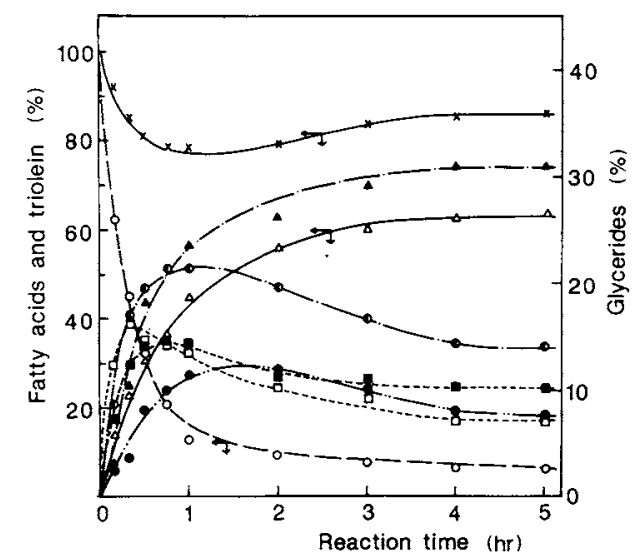

(c)

FIG. 3. Time Courses of the Reaction in $n$-Hexane with the Mucor miehei Lipase Immobilized on Duolite.

Water content $(\%, w / w$-carrier): (a) 0.0882 ; (b) 2.09 ; (c) 10.1 . The symbols for substrates and products are the same as in Fig. 2. 
der the conditions of $50^{\circ} \mathrm{C}$ and $14.7 \mathrm{MPa}$.

These results of preliminary experiments were taken into consideration, and the reaction temperature and pressure finally chosen were $50^{\circ} \mathrm{C}$ and $29.4 \mathrm{MPa}$. The internal state of the reactor was observed through the window of the other high pressure vessel. The $\mathrm{SCCO}_{2} /$ substrate mixtures were faintly opaque, but clearer at $50^{\circ} \mathrm{C}$ and $29.4 \mathrm{MPa}$ than at $35^{\circ} \mathrm{C}$ and 14.7 $\mathrm{MPa}$.

\section{Time course of the reaction}

Figure 2(a) $\sim(c)$ show the time courses of the reactions conducted in $\mathrm{SCCO}_{2}$ with immobilized Mucor miehei lipase. $100 \%$ of each glyceride or free fatty acid corresponds to the initial mole concentration of triolein, oleic acid contained in triolein or stearic acid, respectively. Each reaction was performed at $50^{\circ} \mathrm{C}$ and $29.4 \mathrm{MPa}$, and the water content was 0.0882 in Fig. 2(a), 2.09 in Fig. 2(b) and 10.1\% (w/w-Duolite) in Fig. 2(c), respectively. Through an increase in the water content, the unwanted hydrolysis was promoted to decrease the amount of residual triolein and interesterified triglycerides, and correspondingly to increase those of diglycerides and monoglycerides. It was, however, observed from the initial slope as to concentration that the reaction was favorably accelerated with increasing amounts of water, which will be explained later in detail.

The concentrations of the reaction products are plotted in Fig. 3(a) (c) as a function of reaction time, when water-saturated $n$ hexane was used as the medium. The reaction temperature and the water content were the same as those for the $\mathrm{SCCO}_{2}$ reaction. The time courses of the reaction were almost the same as those in Fig. 2, but the concentration of interesterified triglycerides was a little higher in comparison with in the case of $\mathrm{SCCO}_{2}$, when the water content was $0.0882 \%$ or $2.09 \%$. With a higher water content, i.e., $10.1 \%$, the interesterified triglycerides were rehydrolyzed after about $1 \mathrm{hr}$ in $n$-hexane, and the amount of residual triglycerides became less in equilibrium with the reaction than in the case of the $\mathrm{SCCO}_{2}$ reaction. This result is supposed to be related to the solubility water and triglycerides in the reaction medium, as is discussed later.

\section{Residual triglyceride in equilibrium}

It can be seen in the time courses in Figs. 2 and 3 that the reaction arrived at the equilibrium state in 2 to $6 \mathrm{hr}$ with various water contents in the case of $\mathrm{SCCO}_{2}$, and in $5 \mathrm{hr}$ in the case of $n$-hexane. The data as to the equilibrium concentration of triglycerides were

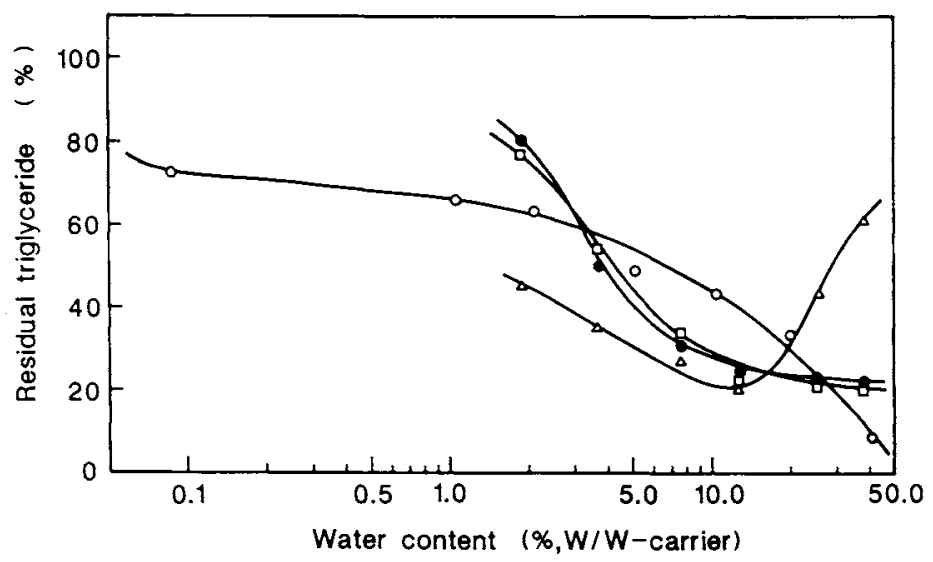

FIG. 4. Effect of the Water Content on the Amount of Residual Triglycerides on Equilibrium of the Reaction in $\mathrm{SCCO}_{2}$ at $50^{\circ} \mathrm{C}$ and $29.4 \mathrm{MPa}$.

Origin of the lipase/carrier: $\bigcirc$, Mucor miehei/Duolite; Celite; $\triangle$, Alcaligenes sp./no carrier. 


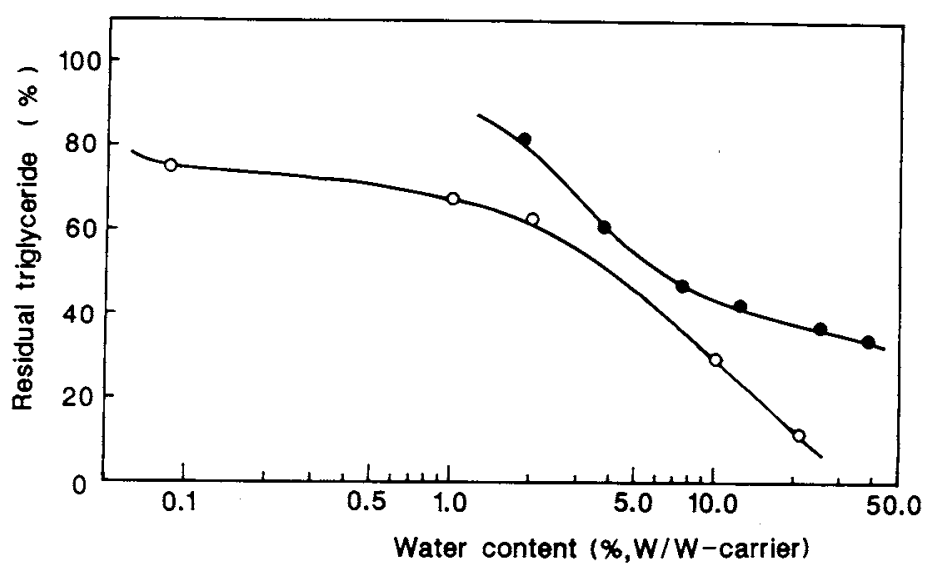

FIG. 5. Effect of the Water Content on the Amount of Residual Triglycerides on Equilibrium of the Reaction in $n$-Hexane at $50^{\circ} \mathrm{C}$.

Origin of the lipase/carrier: $\mathrm{O}$, Mucor miehei/Duolite;

- Rhizopus delemar/Celite.

substituted into Eq. (1) to calculate the amount of residual triglycerides, as shown in Figs. 4 and 5. The lipase of Alcaligenes sp. origin is hydrophobic, and it was difficult to separate the reaction products from the enzyme. Therefore, the amount of residual triglycerides shown in Fig. 4 is that after correction as to the recovery of triglycerides when the lipase of Alcaligenes sp. origin was used.

A higher water content was favorable for the hydrolysis of triglycerides, as mentioned above, and the amount of residual triglycerides decreased with an increase in the water content in the cases of both reaction media, $\mathrm{SCCO}_{2}$ and $n$-hexane, except for in the case of the lipase of Alcaligenes sp. origin. A special profile was obtained, see Fig. 4, for the lipase of Alcaligenes sp. origin, which was supposed not to work well under the conditions of a high water content. The substrate, triolein, remained unaltered, which resulted in a superficial increase in the amount of residual triglycerides when the water content was above $10 \%$. Comparison of the results in Figs. 4 and 5 indicates that in the case of the immobilized lipase of Mucor miehei origin the amount of residual triglycerides is greater in $\mathrm{SCCO}_{2}$ than in $n$-hexane when the water is present in excess. This difference is supposed to be due to the solubilities of water and triglycerides, which differs between in $\mathrm{SCCO}_{2}$ and $n$-hexane.
Chrastil presented a convenient equation for the solubility in $\mathrm{SCCO}_{2},{ }^{17)}$ and it was used to calculate the solubility of some solutes under the present reaction conditions $\left(50^{\circ} \mathrm{C}\right.$ and 29.4 $\mathrm{MPa})$. The solubility of triolein is more than $12 \mathrm{~g} / 1(0.4 \mathrm{~g} / 40 \mathrm{ml})$, while the solubility of tristearin is less than $0.5 / 1(0.02 \mathrm{~g} / 40 \mathrm{ml})$. Therefore, the triglycerides produced through the interesterification reaction are supposed to be less soluble than the substrate, triolein, and a part of them may exist in a separate phase that is excluded from the reaction. The lower solubility of the product triglycerides in $\mathrm{SCCO}_{2}$ could be the reason why the amount of residual triglycerides is greater in $\mathrm{SCCO}_{2}$ than in $n$-hexane. The solubility of water greatly differs between in $\mathrm{SCCO}_{2}(2.5 \mathrm{~g} / 1)$ and $n$ hexane $(0.016 \mathrm{~g} / 1)$. Therefore the water content range used in the experiments was less than the solubility of water in $\mathrm{SCCO}_{2}$, while in the other reaction medium, $n$-hexane, the water content was above this solubility range. In the case of a less adsorptive carrier, diatomaceous earth (Celite), the soluble water content is supposed to be greater in $\mathrm{SCCO}_{2}$ than in $n$ hexane, which moves the equilibrium of the reaction towards the direction of hydrolysis. This is supposed to be the reason why the amount of residual triglycerides was greater in $n$-hexane than in $\mathrm{SCCO}_{2}$ in the case of the lipase immobilized on Celite. 


\section{Extent of interesterification}

Figure 6 shows the effect of the water content on the incorporation of stearic acid into triglycerides, which was measured on equilibrium of the reaction using the four lipases in $\mathrm{SCCO}_{2}$. The results obtained using $n$-hexane as the medium are presented in Fig. 7.

The lipase of Rhizopus sp. origin immobilized on Celite was not active at a water content of less than $1.0 \%$ in either reaction medium, i.e., $\mathrm{SCCO}_{2}$ or $n$-hexane. In the case of $\mathrm{SCCO}_{2}$, the extent of interesterification tended to decrease with increasing water content, probably due to the poorer solubility of stearic acid, which might be partly separated from the reaction medium. On the other hand, the fatty acids and triglycerides were supposed to be very soluble in $n$-hexane, and the extent of interesterification became constant at water contents higher than $10 \%$, because it might obey law of mass action and might be decided primarily by the concentration ratio of fatty acids. The lipase of Alcaligenes sp. origin catalyzed the interesterification reaction in a limited water content range. In the case of the Mucor miehei lipase immobilized on Duolite, the interesterification reaction could occur even at water contents of less than $1 \%$. In the

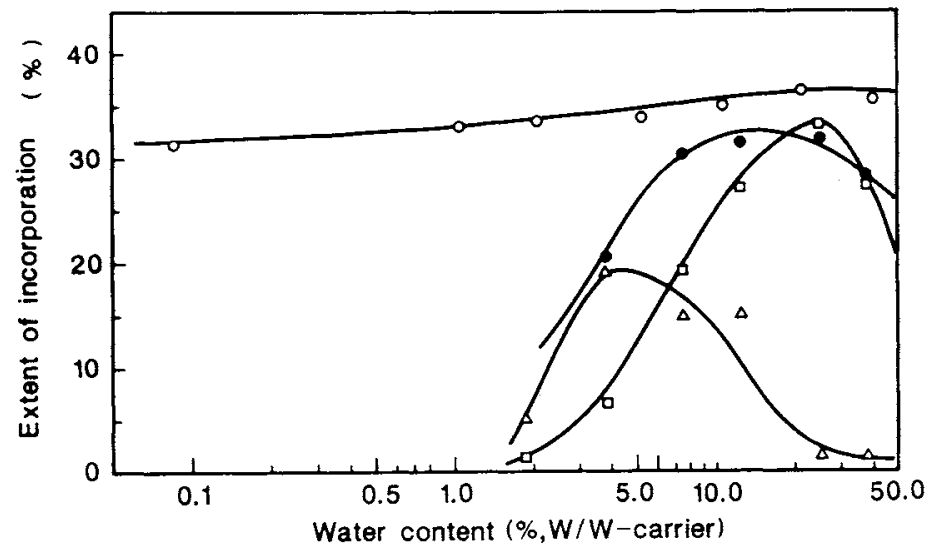

FIG. 6. Effect of the Water Content on the Extent of Interesterification on Equilibrium of the Reaction in $\mathrm{SCCO}_{2}$ at $50^{\circ} \mathrm{C}$ and $29.4 \mathrm{MPa}$.

The symbols are the same as in Fig. 4.

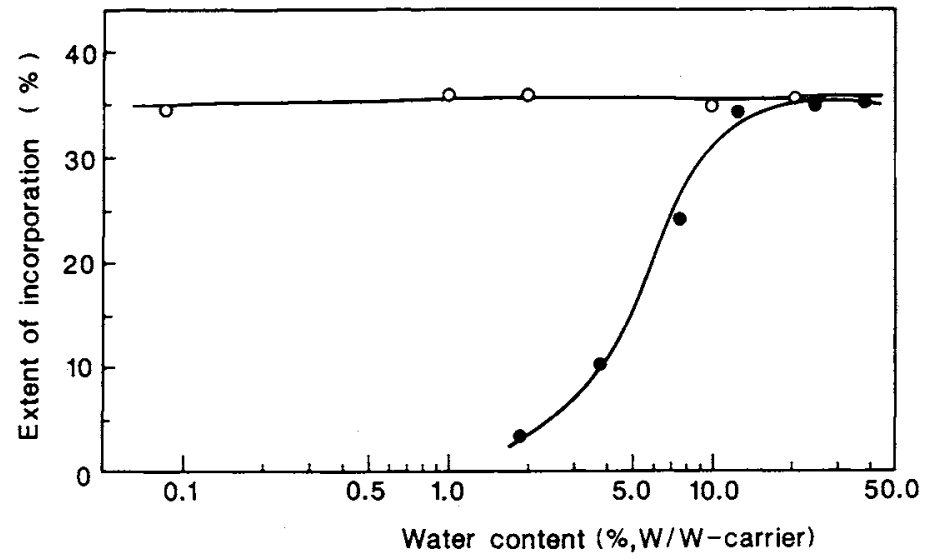

Fig. 7. Effect of the Water Content on the Extent of Interesterification on Equilibrium of the Reaction in $n$ Hexane at $50^{\circ} \mathrm{C}$.

The symbols are the same as in Fig. 5. 
experimental water content range, the extent of interesterification did not change remarkably in either reaction medium, i.e., $\mathrm{SCCO}_{2}$ or $n$-hexane.

The results as to the amount of residual triglycerides and the extent of interesterification showed that the effective water content range differed among the lipases, and this difference could be largely due to the different water sorption isotherms of the carriers. Duolite, with a larger specific surface area, was more water-adsorptive than Celite, which was confirmed by measurement of their sorption isotherms.

\section{Initial velocities of hydrolysis and interesteri- fication}

The effects of the water content on the initial velocities of hydrolysis and interesterification are shown in Figs. 8 and 9, respectively. These results were obtained using the Mucor miehei lipase. When the water content was less than $1 \%$, the initial velocities were not influenced by the kind of reaction medium. The solvent effect, however, became remarkable with an increase in the water content, and the initial velocity in $\mathrm{SCCO}_{2}$ was four times that in $n$-hexane when the water content was $20 \%$. The higher diffusivity of substrates and products, as well as the increase in the dielectric constant of water-containing $\mathrm{SCCO}_{2}$, is supposed to contribute to the increase in the initial velocities. It is expected that the reasons for the solvent effect will be elucidated on analysis of the reaction kinetics, which will be reported in the next paper.

The availability of supercritical carbon dioxide as a medium for enzymatic reactions was investigated in the case of the acidolysis reaction with triolein and stearic acid as substrates. The initial rates of hydrolysis and interesterification were greater in $\mathrm{SCCO}_{2}$ than in $n$-hexane when the commercial immobilized lipase of Mucor miehei origin was used. The improved reaction rates are supposed to be related partly to the functioning of water as a modifier of the solvent property and also as a

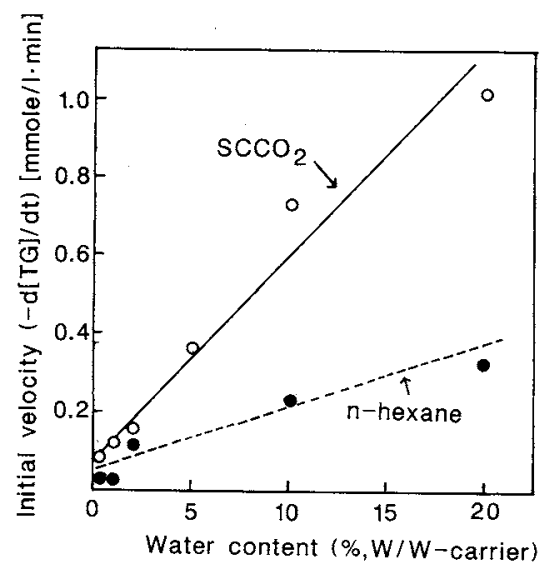

FIG. 8. Effect of the Water Content on the Initial Rate of Hydrolysis.

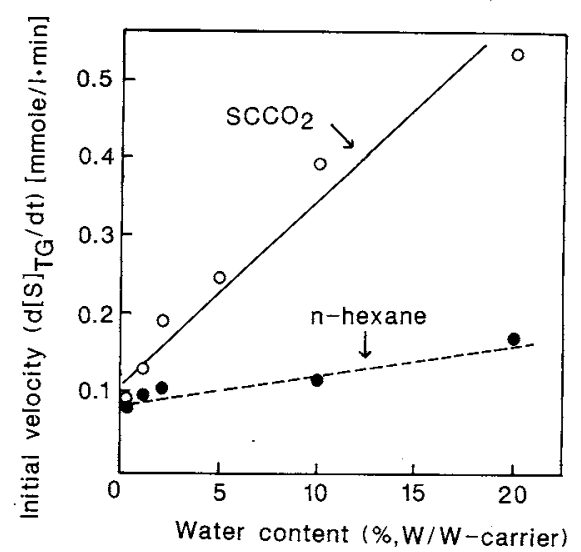

FIG. 9. Effect of the Water Content on the Initial Rate of Interesterification.

substrate. The increase in the reaction rate is a merit of $\mathrm{SCCO}_{2}$, in addition to such advantages as the easiness of the separation of products and its non-toxicity. The results of this study show the potential of supercritical fluids as media for biochemical reactions, and further study should be performed to develop a superctitical fluid bioreactor.

Acknowledgments. The authors express their thanks to Mr. Ed de Jong, Agricultural University, Wageningen, The Netherlands, who worked with them for six months, from 1985 to 1986 , as a foreign research student at the graduate school, and contributed particularly to the setting up of the experimental apparatus. They also acknowledge the kind gifts of the enzymes and carriers from the companies, the names of which are given in the text. This research was supported in part by a Grant-in-Aid for Scientific Research (No. 62860012) from the Ministry of 
Education, Science and Culture of Japan.

\section{REFERENCES}

1) L. F. Randall, Separation Sci. and Technol, 17, 1 (1982).

2) J. K. P. Weder, Z. Lebensm. Unters. Forsch., 171, 95 (1980).

3) J. K. P. Weder, Food Chemistry, 15, 175 (1984).

4) M. Taniguchi, M. Kamihara and T. Kobayashi, Agric. Biol. Chem., 51, 593 (1987).

5) B. Subramanian and M. A. McHugh, Ind. Eng. Chem. Process Des. Dev., 25, 1 (1986).

6) K. Nakamura and T. Yano, Jpn. Pat. Appl. 59143138 (1984) and Jpn. Kokai Tokkyo Koho 6121098 (1986)

7) K. Nakamura, Y. M. Chi, Y. Yamada and T. Yano, Chem. Eng. Commun, 45, 207 (1986).

8) T. W. Randolph, H. W. Blanch, J. M. Prausnitz and
C. R. Wilke, Biotechnol. Lett., 7, 325 (1985).

9) D. A. Hammond, M. Karel, A. M. Klibanov and V. J. Krukonis, Appl. Biochem. Biotechnol, 11, 393 (1985).

10) B. Streenivasan, J. Am. Oil Chem. Soc., 55, 796 (1978).

11) T. Tanaka, E. Ono, M. Ishihara, S. Yamanaka and K. Takinami, Agric. Biol. Chem., 45, 2387 (1981).

12) A. R. Macrae, J. Am. Oil Chem. Soc., 60, 291 (1983).

13) K. Martinek, A. N. Semenov and I. V. Berezin, Biochim. Biophys. Acta, 658, 76 (1981).

14) A. Zaks and A. M. Klibanov, Science, 224, 1249 (1984).

15) H. M. Mohammad, T. Yamane, S. Shimizu, T. Funada and S. Ishida, J. Am. Oil Chem. Soc., 61, 776 (1984).

16) G. Brunner and S. Peter, Separation Sci. and Technol., 17, 199 (1982).

17) J. Chrastil, J. Phys. Chem., 86, 3016 (1982). 